\title{
Neonatal Resuscitation and Postresuscitation Care of Infants Born to Mothers with Suspected or Confirmed SARS-CoV-2 Infection
}

Praveen Chandrasekharan, MD, MS ${ }^{1}$ Maximo Vento, PhD, MD² Daniele Trevisanuto, MD 3 Elizabeth Partridge, MD ${ }^{4}$ Mark A. Underwood, MD ${ }^{5}$ Jean Wiedeman, MD ${ }^{4}$ Anup Katheria, MD Satyan Lakshminrusimha, $\mathrm{MD}^{5}$

\footnotetext{
${ }^{1}$ Division of Neonatology, Department of Pediatrics, Oishei Children's Hospital of Buffalo, University at Buffalo, Buffalo, New York

${ }^{2}$ Division of Neonatology, University and Polytechnic Hospital La Fe, Valencia, Spain

3 Department of Pediatrics, University-Hospital of Padova, Padova, Italy

${ }^{4}$ Division of Infectious Disease, Department of Pediatrics, University of California, Davis, California

${ }^{5}$ Division of Neonatology, Department of Pediatrics, University of California, Davis, California

${ }^{6}$ Sharp Mary Birch Hospital for Women and Newborns, San Diego, California
}

Address for correspondence Praveen Chandrasekharan, MD, MS, Division of Neonatology, Department of Pediatrics, Oishei Children's Hospital of Buffalo, University at Buffalo, Buffalo, NY 14203 (e-mail: pkchandr@buffalo.edu).

Am J Perinatol 2020;37:813-824.

\begin{abstract}
Keywords

- neonatal resuscitation

- COVID-19

- novel coronavirus

- SARS-CoV-2

The first case of novel coronavirus disease of 2019 (COVID-19) caused by severe acute respiratory syndrome-coronavirus 2 (SARS-CoV-2) was reported in November 2019. The rapid progression to a global pandemic of COVID-19 has had profound medical, social, and economic consequences. Pregnant women and newborns represent a vulnerable population. However, the precise impact of this novel virus on the fetus and neonate remains uncertain. Appropriate protection of health care workers and newly born infants during and after delivery by a COVID-19 mother is essential. There is some disagreement among expert organizations on an optimal approach based on resource availability, surge volume, and potential risk of transmission. The manuscript outlines the precautions and steps to be taken before, during, and after resuscitation of a newborn born to a COVID-19 mother, including three optional variations of current standards involving shared-decision making with parents for perinatal management, resuscitation of the newborn, disposition, nutrition, and postdischarge care. The availability of resources may also drive the application of these guidelines. More evidence and research are needed to assess the risk of vertical and horizontal transmission of SARS-CoV-2 and its impact on fetal and neonatal outcomes.
\end{abstract}

Key Points

- The risk of vertical transmission is unclear; transmission from family members/providers to neonates is possible.

- Optimal personal-protective-equipment (airborne vs. droplet/contact precautions) for providers is crucial to prevent transmission.

- Parents should be engaged in shared decision-making with options for rooming in, skin-to-skin contact, and breastfeeding.

received

March 30, 2020

accepted

March 30, 2020

published online

April 8, 2020
Copyright $\odot 2020$ by Thieme Medical Publishers, Inc., 333 Seventh Avenue, New York, NY 10001, USA. Tel: +1(212) 760-0888.
DOI https://doi.org/ 10.1055/s-0040-1709688. ISSN 0735-1631. 
The emergence of the novel virus known as severe acute respiratory syndrome-corona virus 2 (SARS-CoV-2) has led to the global pandemic, novel coronavirus disease of 2019 (COVID-19). ${ }^{1,2}$ China reported the first case of SARS-CoV-2 infection on November 17, 2019. ${ }^{3}$ Within 2 months, on January 20, 2020, a traveler from Wuhan was the first reported case of COVID-19 in the United States. ${ }^{4}$ With a rapid rate of transmission, 972,640 confirmed cases of COVID-19 have been reported globally as of April 3, 2020 with 50,325 deaths. ${ }^{1}$ With a wide spectrum of presentation of the illness, and the inability to adequately screen the population at risk, these numbers underestimate the rate of transmission and its global impact on morbidity and mortality. As of 2016, women in the childbearing age group represent $20 \%$ of U.S. population. ${ }^{5}$ As per the Centers for Disease Control and Prevention (CDC), it is not known if pregnant mothers are at increased risk of acquiring SARS-CoV-2 infection or whether they are at more risk for developing serious illness as a result. ${ }^{6}$ It remains unclear if vertical transmission of the virus occurs during pregnancy. Limited evidence suggests that vertical transmission in utero is rare including a report of nine pregnant infected women in China whose infants all tested negative for the virus. ${ }^{7}$ However, more recently, immunoglobulin (Ig)-M antibodies have been detected in newly born infants, although viral RNA has not been isolated, suggesting a possibility of vertical transmission. In addition, disruption of the placental barrier in placental abruption or maternal-fetal hemorrhage may potentially transmit the virus and/or IgM antibodies to the fetal circulation. Based on our knowledge of other viruses that cause severe respiratory illness (influenza, SARS-CoV, and
Middle East Respiratory Syndrome Coronavirus [MERS$\mathrm{CoV}])$, neonates, especially those born preterm, are at increased risk of acquiring COVID-19 postnatally secondary to an immature immune system. Resuscitating a neonate born to a mother suspected or confirmed to have COVID-19 poses a risk to the neonate and health care providers. With limited availability of literature to guide perinatal management, the intent of this manuscript is to provide a stepwise approach to resuscitating, stabilizing, and providing postnatal care to an infant born to a mother who is suspected or has confirmed COVID-19. As more evidence becomes available, these guidelines are likely to evolve.

\section{Obstetric Patient under Investigation for COVID-19}

The range of illnesses reported among pregnant women with COVID-19 is variable. In the previously noted case series by Chen et al involving nine pregnant women with COVID-19, the signs and symptoms of pneumonia were similar to nonpregnant adult patients. ${ }^{7}$ In a report including 32 pregnant women affected by COVID-19, 7 were asymptomatic, 1 required intensive care, and 1 was placed on extracorporeal membrane oxygenation (ECMO) support. $^{8}$

A suspected or confirmed case of COVID-19 should be handled as per $\mathrm{CDC}$ recommendations depending upon each institutional obstetric facility and availability of resources. ${ }^{9}$ For source-containment, the pregnant woman must wear a mask (-Fig. 1). While transporting an obstetric patient who is a person under investigation (PUI) for SARS-CoV-2 infection, health care providers should wear proper personal

\section{Prescreen pregnant woman and partner/visitor prior to arrival at the hospital}

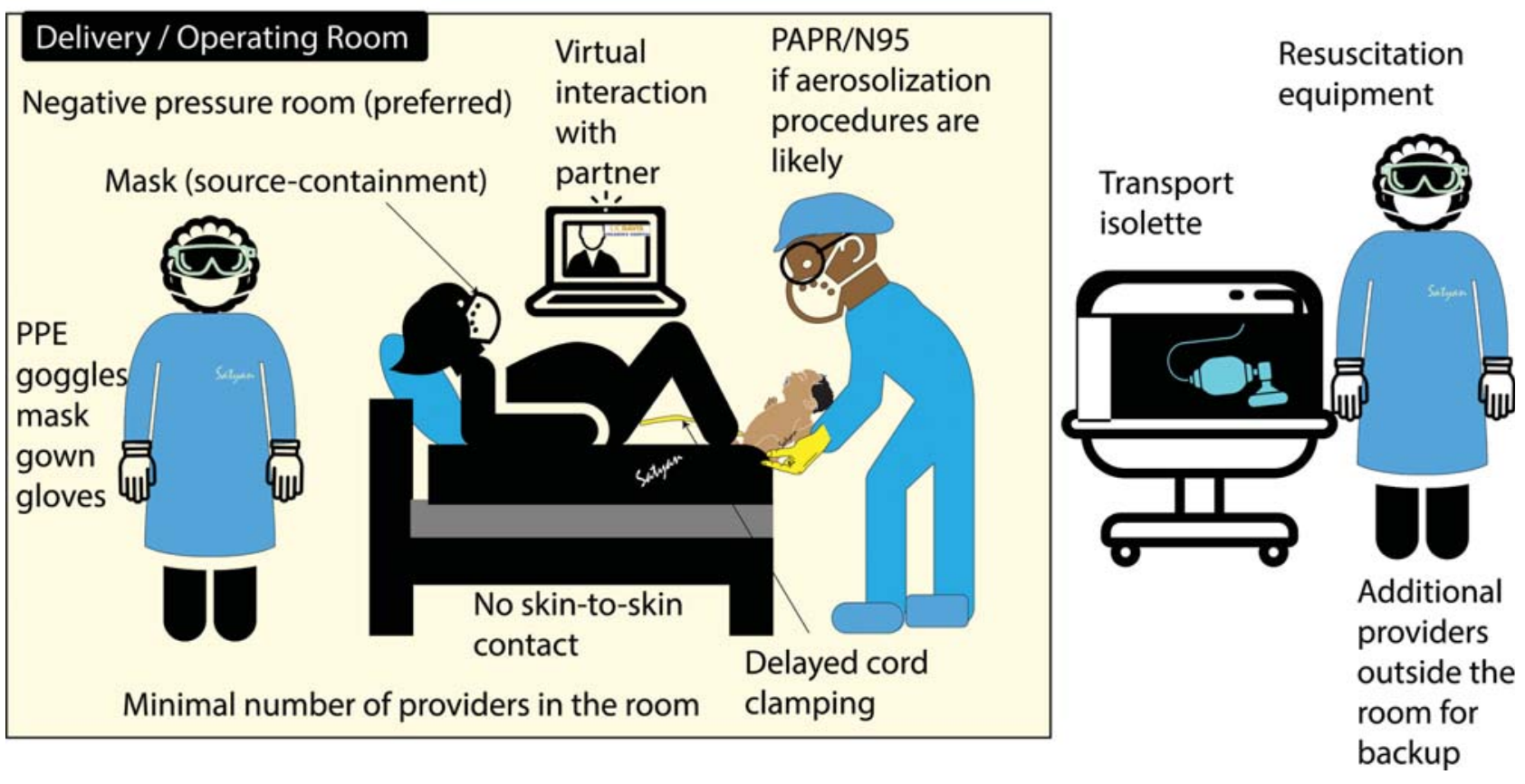

Fig. 1 Setting up of a birthing room for a patient with suspected or confirmed COVID-19 undergoing labor and delivery. A negative pressure room is preferred with limited number of providers in the room to limit exposure. Additional personnel may be outside the room and be available if extensive neonatal resuscitation is needed. COVID-19, novel coronavirus disease 2019; PAPR, powered air-purifying respirator. Image Courtesy: Satyan Lakshminrusimha. 
protective equipment (PPE). This includes contact and droplet precautions (mask with goggles/face-shield, gown, and gloves). The following pertinent information should be collected: recent history of contact with a known infected person, gestational age at exposure and time of labor, existing medical illness including pregnancy complications. Pregnant women with clinical signs and symptoms consistent with "influenza-like illness (ILI)" should undergo testing for SARS-CoV-2. Testing includes nasopharyngeal and oropharyngeal swabs placed in a viral transport medium for RNA detection (typically real-time polymerase chain reaction [RT-PCR]). A designated team of health care providers with appropriate PPE should care for these patients preferably in a negative pressure room.

\section{Approach to Birth, Resuscitation, and Postnatal Care}

Case series published, to date, suggest a higher than expected number of preterm deliveries (15 out of 32 deliveries were preterm. ${ }^{7,8,10-12}$ The extent to which maternal COVID-19 infection increases risk of preterm delivery remains unclear, though there are several unpublished reports of preterm delivery due to severe maternal infection (bilateral pneumonia with respiratory insufficiency and shock). Until there is more extensive testing, the probability of reporting bias remains high.

In Spain, based on data from at least 25 pregnant women, prematurity was secondary to an obstetric decision to deliver due to the severity of the infection in the mother (bilateral pneumonia with respiratory insufficiency and shock). If the mother was asymptomatic or mildly symptomatic, gestation was allowed to progress (unpublished data from the Spanish Maternal and Neonatal Network; Health Research Institute Carlos III; Ministry of Science and Innovation).

\section{Presurgery Preparation of Staff in Obstetric and Neonatal Division}

Prior to the surgery, it is crucial to plan for additional delivery rooms, personnel, and simulations to care for an obstetric patient with COVID-19 and her newborn. Make-shift delivery and operation rooms may need to be in place with proper PPE for the patients and health care providers in regions anticipating a surge. Simulations to handle delivery room situations are important to understand the logistics, workflow, safety equipment during resuscitation, and transition of care from the birthing room to nursery/neonatal intensive care unit (NICU). Additional rooms for testing and safely discarding kits and disinfecting delivery and operation rooms should be in place.

\section{Prenatal Consult and Preparations for Delivery}

If a prenatal consultation is required, especially in births associated with extreme prematurity, outcomes based on gestational age, and available data should be discussed using phone/video to minimize exposure to healthcare providers. In situations where a full prenatal consultation is not possible, the obstetric and neonatal team should discuss optimal management and involve parents in shared decision making through phone/video consultation.

Recent media reports suggest an uptick in pregnant mothers seeking home deliveries. These deliveries pose additional challenges to health care workers and transmission risk to neonates.

Preparation for delivery of a suspected COVID-19 woman is shown in -Fig. 1. The benefits and risks of skin-to-skin contact, delayed cord clamping (DCC), immediate separation of the infant from the mother and nutrition strategies should be reviewed with the parents (-Table 1; - Fig. 2). This discussion should include recognition that our understanding of these risks and benefits is limited, with no data on long-term developmental outcomes in COVID-19 positive neonates and risks to other family members and health care workers must also be factored into shared decision making.

The mother should be transported to labor and delivery with a mask for source-containment with precautions to minimize exposure to health care workers. This process includes screening before (by phone or video visit) and upon hospital entry. The possibility of infection in the mother's partner should be considered and addressed as per the hospital's visitation policy. Most centers will screen visitors and prevent them from being present during labor and delivery if they have risk factors or signs or symptoms of COVID-19. Interaction with the spouse/partner through digital media is an option (-Fig. 1). New York state recently issued an advisory that one support person (asymptomatic and screened negative for COVID-19) is essential for patient care during delivery (https://coronavirus.health.ny.gov/system/files/documents/2020/03/doh_covid19_obpedsvisitation_032720.pdf). The number of providers (obstetric and neonatal) in the delivery room should be minimized to limit exposure. Additional providers might stay outside the delivery room and be summoned in case of an emergency.

\section{Use of Antenatal Steroids}

The effect of administering antenatal steroids (ANS) in a COVID-19 mother for possible premature delivery remains unknown. The beneficial effects of ANS for preterm neonates differ in resource-rich and resource-limited areas. How this risk:benefit ratio is altered by COVD-19 is unknown. ${ }^{13,14}$ The immunosuppressive effect of steroids could affect maternal response to infection in COVID-19. Variations in neonatal mortality following ANS in different countries and the plausible association with infection raises concern about its use with coexisting COVID-19. ${ }^{15}$ However, maternal influenza and human immunodeficiency virus (HIV) infections are not contraindications to ANS administration. Yet, careful consideration is warranted regarding the potential morbidity of the premature infant. ANS are known to accelerate the development of type- 2 alveolar cells in the lung, cells that are rich in angiotensin-converting enzyme 2, a coreceptor for SARS$\mathrm{CoV}-2$ viral entry. However, this theoretical risk is countered by a significant decrease in mortality and morbidity in preterm infants following ANS. There is currently no evidence to support or refute ANS in mothers with COVID-19 with impending preterm delivery. Obstetric providers 
816 Care of a Newborn with Suspected or Confirmed COVID-19 Chandrasekharan et al.

Table 1 Options based on shared-decision making with parents to manage an infant born to a mother suspected or confirmed with COVID-19

\begin{tabular}{|c|c|c|c|}
\hline Scenario & Option A & Option B & Option C \\
\hline Delivery & $\begin{array}{l}\text { Necessary precautions as recom- } \\
\text { mended by CDC delivery and re- } \\
\text { suscitation in negative pressure } \\
\text { room }\end{array}$ & $\begin{array}{l}\text { Necessary precautions as recom- } \\
\text { mended by } C D C \text { with designated } \\
\text { negative pressure room or isolation } \\
\text { room }\end{array}$ & $\begin{array}{l}\text { Necessary precautions as recom- } \\
\text { mended by CDC in an isolation } \\
\text { room }\end{array}$ \\
\hline Visitor policy at delivery & $\begin{array}{l}\text { No visitors/partners allowed, video } \\
\text { link only }\end{array}$ & $\begin{array}{l}\text { One visitor/partner/spouse allowed } \\
\text { following screen for COVID-19 }\end{array}$ & $\begin{array}{l}\text { One or two visitors allowed follow- } \\
\text { ing screening for COVID-19 }\end{array}$ \\
\hline Neonatal resuscitation & $\begin{array}{l}\text { The resuscitation is performed in a } \\
\text { separate negative pressure room }\end{array}$ & $\begin{array}{l}\text { The resuscitation is performed in } \\
\text { the delivery room } 6 \text { feet or } 2 \text { m away } \\
\text { from the mother with a curtain/ } \\
\text { physical barrier with limited pro- } \\
\text { viders in a negative pressure room }\end{array}$ & $\begin{array}{l}\text { The resuscitation is performed in } \\
\text { the delivery room } 6 \text { feet or } 2 \text { m away } \\
\text { from the mother with limited pro- } \\
\text { viders in an isolation room }\end{array}$ \\
\hline Delayed cord clamping & $\begin{array}{l}\text { No delayed cord clamping under } \\
\text { any circumstance }\end{array}$ & $\begin{array}{l}\text { Delayed cord clamping in asymp- } \\
\text { tomatic or mildly symptomatic } \\
\text { mothers }\end{array}$ & $\begin{array}{l}\text { Delayed cord clamping in all } \\
\text { mothers }\end{array}$ \\
\hline Skin-to skin care & No skin-to-skin contact & $\begin{array}{l}\text { Skin-to-skin contact only in asymp- } \\
\text { tomatic mothers (with a } \\
\text { mask + hand hygiene) }\end{array}$ & $\begin{array}{l}\text { skin-to-skin contact only in asymp- } \\
\text { tomatic and mildly symptomatic } \\
\text { mothers (with a mask + hand } \\
\text { hygiene) }\end{array}$ \\
\hline Infant placement & $\begin{array}{l}\text { Separate negative pressure room in } \\
\text { nursery/neonatal intensive care } \\
\text { unit depending on gestational age/ } \\
\text { birth weight }\end{array}$ & $\begin{array}{l}\text { Negative pressure room with infant } \\
\text { in an isolette with visits from the } \\
\text { mother wearing a mask and per- } \\
\text { forming careful and frequent hand } \\
\text { hygiene }\end{array}$ & $\begin{array}{l}\text { In the same room with mother, } \\
\text { infant cared in an isolette, but kept } \\
6 \text { feet or } 2 \mathrm{~m} \text { from mother except } \\
\text { during feeding; mother wears a } \\
\text { mask + hand hygiene }\end{array}$ \\
\hline Neonatal testing & $\begin{array}{l}\text { Nasopharyngeal, oropharyngeal } \\
\text { and rectal swabs at } 24 \text { and } 48 \text { hours } \\
\text { after birth (six swabs) }\end{array}$ & $\begin{array}{l}\text { Nasopharyngeal/oropharyngeal at } \\
\text { 24-hour after birth (2-3 swabs) }\end{array}$ & $\begin{array}{l}\text { No testing of neonate if } \\
\text { asymptomatic }\end{array}$ \\
\hline $\begin{array}{l}\text { Maternal testing to end trans- } \\
\text { mission precautions }\end{array}$ & $\begin{array}{l}\text { Afebrile (without antipyretics) and } \\
\text { improvement of symptoms and } 2 \\
\text { nasopharyngeal and oropharyngeal } \\
\text { swabs for SARS-CoV- } 2 \text { testing are } \\
\text { negative } \times 2 \text { at least } 24 \text {-hour apart }\end{array}$ & $\begin{array}{l}\text { Afebrile (without antipyretics) and } \\
\text { improvement of symptoms and } 2 \\
\text { nasopharyngeal and oropharyngeal } \\
\text { swabs for SARS-CoV- } 2 \text { testing are } \\
\text { negative } \times 1\end{array}$ & $\begin{array}{l}\text { Afebrile (without antipyretics) and } \\
\text { improvement of symptoms }\end{array}$ \\
\hline Visitation policy for infant & $\begin{array}{l}\text { Restrict mother's and other family } \\
\text { members' visitation until two } \\
\text { specimens are negative and mother } \\
\text { is asymptomatic. If possible, allow } \\
\text { video visitation }\end{array}$ & $\begin{array}{l}\text { Mother can visit. Restrict other vis- } \\
\text { itors. Allow video visitation }\end{array}$ & $\begin{array}{l}\text { One visitor who has been screened } \\
\text { could visit mother and baby }\end{array}$ \\
\hline $\begin{array}{l}\text { Infant exposed to COVID-19 } \\
\text { positive healthcare provider }\end{array}$ & $\begin{array}{l}\text { Isolate baby in a negative pressure } \\
\text { room and isolette and resume reg- } \\
\text { ular care only after two specimens } \\
\text { at least } 24 \text {-hour apart test negative } \\
\text { with no symptoms }\end{array}$ & $\begin{array}{l}\text { Care in an isolette until two speci- } \\
\text { mens at least } 24 \text {-hour apart test } \\
\text { negative with no symptoms }\end{array}$ & Test infant only if symptomatic \\
\hline $\begin{array}{l}\text { Discharge plans and postdi- } \\
\text { scharge care }\end{array}$ & $\begin{array}{l}\text { The newborn could be transferred } \\
\text { to a healthy caregiver until mother } \\
\text { is afebrile (without antipyretics) } \\
\text { with improvement of symptoms } \\
\text { and } 2 \text { nasopharyngeal and oropha- } \\
\text { ryngeal swabs for SARS-CoV- } 2 \text { test- } \\
\text { ing are negative } \times 2 \text { at least } 24 \text {-hour } \\
\text { apart }\end{array}$ & $\begin{array}{l}\text { Discharge to mother with contact } \\
\text { and droplet precautions until } \\
\text { mother is afebrile (without antipy- } \\
\text { retics) with improvement of symp- } \\
\text { toms and } 2 \text { nasopharyngeal and } \\
\text { oropharyngeal swabs for SARS-CoV- } \\
2 \text { testing are negative } \times 2 \text { at least } \\
24 \text {-hour apart }\end{array}$ & $\begin{array}{l}\text { Discharge home with mother with } \\
\text { contact and droplet precautions; no } \\
\text { further maternal testing unless } \\
\text { symptoms/signs do not resolve in } \\
14 \text { days or her condition } \\
\text { deteriorates }\end{array}$ \\
\hline $\begin{array}{l}\text { Infant testing and follow-up af- } \\
\text { ter discharge }\end{array}$ & $\begin{array}{l}\text { Test infant with nasopharyngeal, } \\
\text { oropharyngeal at 2-3 weeks after } \\
\text { discharge } \\
\text { Frequent video visits or phone calls }\end{array}$ & $\begin{array}{l}\text { Test infant with nasopharyngeal, } \\
\text { oropharyngeal at } 2-3 \text { weeks only } \\
\text { if previously negative; Frequent } \\
\text { video visits or phone calls }\end{array}$ & $\begin{array}{l}\text { No further testing unless infant is } \\
\text { symptomatic; Frequent video visits } \\
\text { or phone calls }\end{array}$ \\
\hline $\begin{array}{l}\text { Potential risk of transmission to } \\
\text { neonate }\end{array}$ & Low & Unknown but possible & Unknown but could be moderate \\
\hline
\end{tabular}

Abbreviations: CDC, Centers for Disease Control and Prevention; COVID-19, novel coronavirus disease-2019; EBM, expressed breast milk; PPE, personal protective equipment; SARS-CoV-2, severe acute respiratory syndrome-coronavirus 2.

Note: each option listed in this table could be modified based on institutional preference to develop an individual policy based on available resources, facility and patient volume. The predominant factor driving these choices is maternal acceptance of risk of transmission. Each center may adopt different options for each row and come up with an algorithm. An example of such an algorithm at UC Davis Medical Center is shown in - Fig. 2. 


\section{CARE OF NEONATES BORN TO PREGNANT WOMEN WITH SUSPECTED OR CONFIRMED SARS-COV-2 INFECTION}

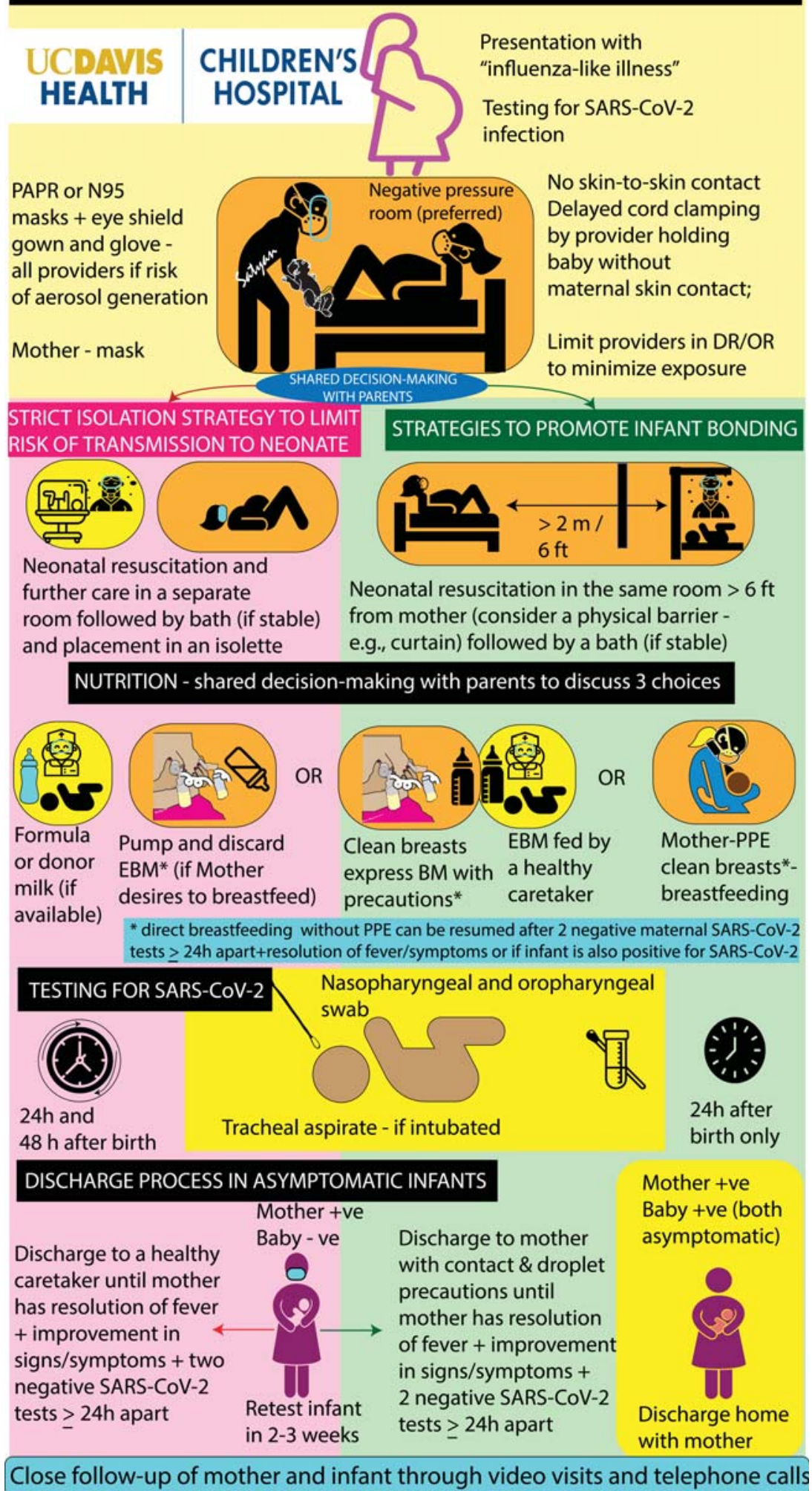

Fig. 2 Infographic showing the approach to neonates born to mothers with suspected or confirmed COVID-19 including a combination of options A, B, and C ( - Table 1) based on decisions made with parental involvement, at the University of California at Davis Medical Center. The pink panel reflects a conservative approach with strict isolation methods to limit viral transmission to the neonate at the cost of maternal-infant bonding. The green panel shows strategies to minimize transmission while accommodating maternal-infant bonding and breastfeeding. The risk of infection with such an approach must be emphasized during discussion with parents. Please see text and $=$ Table 1 for details. DR, delivery room; EBM, expressed breast milk; OR, operating room; PAPR, powered air-purifying respirator; PPE, personal protective equipment; SARS-CoV2, severe acute respiratory syndrome-coronavirus 2. Image Courtesy: Satyan Lakshminrusimha. 
should discuss the known benefits and unknown risks associated with ANS in mothers with confirmed COVID-19 with the pregnant woman, and clinical decisions made on a caseby-case basis. The use of magnesium sulfate and other maternal interventions are continued as per standard obstetric protocols.

\section{Mode of Delivery and Anesthesia}

The mode of delivery and anesthesia is best decided as per maternal and fetal indications by the obstetric and anesthesia teams. There is no evidence to suggest one mode of delivery is preferred over the other. Cesarean delivery in the operating room (OR) will result in exposure to a larger number of health care workers compared with spontaneous vaginal delivery. Endotracheal intubation of the mother for general anesthesia will increase the risk of droplet generation compared with spinal anesthesia. For women presenting with sudden and severe respiratory insufficiency, general anesthesia should be considered if their respiratory status requires mechanical ventilation.

\section{Equipment}

If there is a potential need for aerosol-generating procedures (continuous positive airway pressure (CPAP), intubation/ extubation, deep suctioning, etc.), PPE should include powered air-purifying respirator (PAPR) or goggles with an N95 mask plus gown and gloves. Since it is not possible to predict which infants will require intubation or deep suctioning, the neonatal team may consider wearing airborne PPE for all deliveries of COVID-19 positive or suspected women. Prescription eyeglasses do not offer adequate eye protection. Spontaneous vaginal delivery and cesarean section are considered exposure to bodily fluid, and airborne precautions are usually not necessary for the obstetric team. However, N95 fit-tested masks may be used for added protection (if available) or if there is a high potential for an aerosolgenerating procedure. In some hospitals, T-piece resuscitator is preferred over the bag and mask ventilation. Both antibacterial filters and viral filters are available that could be connected to the circuit. ${ }^{16}$

A complete updated description regarding PPE, its proper use and disposal is available at the CDC web site. ${ }^{6,9}$

\section{Amniotic Fluid and Meconium Staining}

The report by Chen et al tested six samples of amniotic fluid from COVID-19 mothers and all were negative for SARS CoV2. Current guidelines do not recommend routine intubation for either vigorous or nonvigorous infants with meconiumstained amniotic fluid and no evidence has been presented to suggest this guideline should be altered for the COVID-19 delivery.

\section{Skin-to-Skin Contact and Kangaroo Mother Care}

A recent guideline from the World Health Organization $(\mathrm{WHO})^{17}$ suggested that mothers and infants with suspected, probable, or confirmed COVID-19 be given the option to remain together with skin-to-skin contact, especially immediately after birth during the establishment of breastfeeding.
A more restrictive approach recommended by the Chinese guidelines ${ }^{18}$ and Spanish guidelines ${ }^{19}$ focuses on minimizing the risk of exposure to the infant by avoiding direct skin-toskin contact after delivery, including placement of the infant on the maternal abdomen. Shared decision-making with the parents before delivery regarding the potential risks and benefits of skin-to-skin care and kangaroo mother care is recommended. Such a discussion should include risks of exposure to both the neonate and to health care providers.

\section{Umbilical Cord Management}

The Chinese expert consensus guideline suggests that infants born to mothers with suspected or confirmed COVID-19 should receive immediate cord clamping to mitigate the possibility of transplacental passage. ${ }^{18}$ Currently, there are no cases of confirmed vertical transmission diagnosed by detecting viral RNA from a mother to a fetus. ${ }^{20}$ Given that the fetus has exchanged the same blood supply during the entire pregnancy, if vertical transmission was possible, it would likely have occurred before delivery. However, recent reports of elevated COVID-19 IgM levels in three newborn infants born to mothers with COVID-19 positive have raised concerns about vertical transmission. ${ }^{21-23}$ None of these neonates were positive for SARS-CoV-2. Thus current evidence suggests that vertical transmission is probably uncommon and more evidence is needed.

DCC for the vigorous infant allows for a redistribution of placental blood back to the infant and maintains preload, as the lungs are recruited, and as such, does not increase the risk of vertical transmission. This is consistent with recommendations of mothers infected with viruses known to cause transplacental infection such as HIV. ${ }^{24}$ The benefits for DCC include increased hemoglobin and iron, ${ }^{25}$ Igs and stem cells, ${ }^{26}$ and improved neurodevelopment. ${ }^{27}$ These benefits outweigh the unlikely risk for acquiring COVID-19 through DCC. DCC should be performed for at least 60 seconds if the baby is vigorous. Ventilating an infant with DCC in this instance is not recommended to reduce the risk of exposure to health care personnel. Whether the baby is placed on the mother's abdomen or held by the obstetrician during DCC should be discussed with the mother prior to delivery as mentioned previously. We recommend that the obstetric provider hold the baby during DCC. In some centers, immediate cord clamping is preferred if mother is symptomatic (fever, cough, and other respiratory symptoms), to minimize exposure in the delivery room. Currently, there is no evidence to support other modes of placental transfusion such as umbilical cord milking.

\section{Delivery}

Delivery of a suspected or confirmed COVID-19 patient should preferably take place in a center with the capacity to care for critically ill adults and neonates and in a negative pressure room. The neonatology/newborn team should be informed, ideally 30 to 60 minutes before delivery. Appropriate PPE should be available for the neonatal team. Centers could have a PPE grab and go kit containing approximately six face shields or goggles, six N95 masks and gloves, and gowns, 
readily available for the neonatal resuscitation team. If a mother needs a cesarean section, additional PPE (or PAPR carts) should be available for added health care team members. In some countries and places with a higher number of COVID-19 cases, ad hoc delivery rooms, and operating rooms have been designated for these patients. In some hospitals, outborn infants are routed to designated paths, thus avoiding the emergency room.

The designated delivery/operating room, should have adequate equipment including a radiant warmer, airway accessories (suction, facemask, endotracheal tube, laryngeal airway, positive pressure apparatus, oxygen, and blender) and a cart with medications/fluids/umbilical catheter placement kit for advanced resuscitation as recommended by the American Academy of Pediatrics (AAP) and Neonatal Resuscitation Program (NRP).

\section{Designated Resuscitation Team}

Hospital facilities could consider the designation of a specific newborn resuscitation team to attend deliveries of mothers with suspected or confirmed COVID-19. A designated team in a high-volume birthing center could potentially minimize exposure and transmission of SARS-CoV-2 among health care providers and from infected mothers to noninfected mothers and infants. A minimum number of neonatal resuscitators should be in the room, with the rest of the team being available outside the room.

\section{Stabilization and Resuscitation of the Neonate}

The current AAP and NRP recommendations in the delivery room should be followed. ${ }^{28}$ The optimal location for neonatal stabilization and resuscitation is not clear. It can be conducted in an adjacent room or the same place at least 6 feet or $2 \mathrm{~m}$ away from the mother with a physical barrier such as a curtain (-Fig. 3). It is preferable to conduct resuscitation in an isolette with a hood that can be elevated to provide warmth for resuscitation and then lowered for transport. Regardless of gestational age, the newborn should be transported in a closed isolette and maintained in the isolette for postresuscitation care.

\section{Airway Management}

A newborn airway should be managed as per NRP recommendations. ${ }^{28}$ Clearing the airway by suctioning could generate aerosols. Adequate PPE as mentioned previously will protect the providers present in the delivery room. "In a neonate who requires positive pressure ventilation (PPV), the resuscitation is performed as per AAP and NRP recommended parameters and target saturations with supplemental oxygen." Personnel involved in the placement of an advanced airway, such as an endotracheal tube, should take precautions by wearing fit-tested N95 masks/PAPR, face shields/goggles, and double gloves before the procedure. The most experienced provider should perform intubation and other procedures to limit aerosol generation.

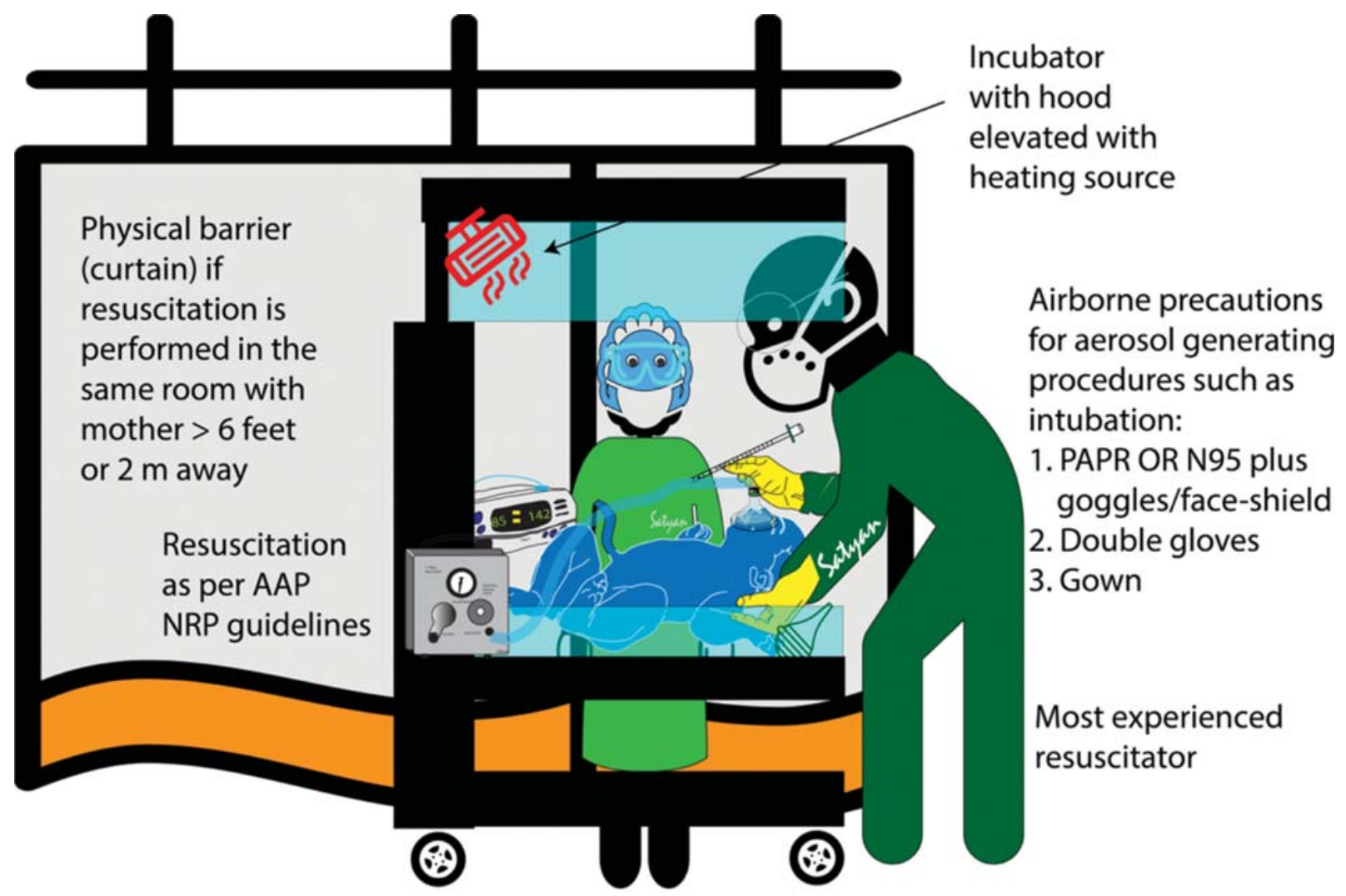

Limited number of providers in the resucitation room

Fig. 3 Resuscitation in the delivery room with precautions to minimize risk to the infant. Appropriate PPE and maintaining at least 6-feet or 2-m distance from the mother with a barrier (curtain) in between is important. Alternatively, infant may be resuscitated in a separate room. AAP, American Academy of Pediatrics; NRP, Neonatal Resuscitation Program; PAPR, powered air-purifying respirator. Image Courtesy: Satyan Lakshminrusimha. 
It remains unclear if use of a T-piece resuscitation device to provide CPAP/PPV via facemask could generate aerosols. Close ventilator circuits with appropriate bacterial/viral filters and sealed mask will minimize leakage. However, with reported 50 to $60 \%$ leakage during mask ventilation in the delivery room, especially with premature neonates, ${ }^{29}$ appropriate PPE for resuscitators are extremely important. It is considered that laryngeal mask airway (LMA) reduces aerosol generation and could be an alternative to face mask ventilation. ${ }^{30}$ Open suction of endotracheal tube while administering surfactant or clearing secretions could generate aerosols, and a provider should anticipate such situations and be prepared.

\section{Advanced Resuscitation}

Chen et al do not report neonatal depression/asphyxia in the nine livebirths to mothers with COVID-19. However, it is unknown whether maternal COVID-19 infection increases risk for severe neonatal depression requiring chest compressions and epinephrine administration as per NRP guidelines. ${ }^{28}$ An infant born to a mother with COVID-19 severe acute respiratory distress under general anesthesia could be depressed and may require resuscitation either as a consequence of maternal respiratory disease or anesthesia. As with non-COVID-19 resuscitations, fluid boluses and blood products are needed in special circumstances, such as severe blood loss due to placental abruption, with precautions recommended by $\mathrm{CDC}^{9}{ }^{9}$ Currently, it remains unknown whether maternal COVID-19 alters the outcomes of neonates requiring advanced resuscitation.

\section{Disposition of the Newborn}

Poststabilization, the newborn should be transported in a closed isolette and isolated in a negative pressure room. The disposition to the newborn nursery/mother-baby unit/NICU is made based on gestational age, newborn's condition, need for antibiotics, intravenous fluids, respiratory support, maternal condition postdelivery, and individual hospital policies. A specialized team caring for newborns born to COVID19 mothers could minimize the transmission and spread of the SARS-CoV-2 among health care workers.

An early bath to minimize exposure can be considered in stable term newborn infants born to a mother with suspected or confirmed COVID-19.

\section{Nutritional Support}

The optimal mode of nutrition for an infant born to COVID-19 mother is not known. The benefits of breastfeeding should be weighed against the risk of transmission of SARS-CoV-2. No reports are demonstrating SARS-CoV-2 virus in breastmilk ${ }^{7}$; in contrast, antibodies to SARS-CoV-2 have been detected in breastmilk in anecdotal reports. For COVID-19 positive mothers whose infants are still negative or pending a test, three approaches can be considered. A shared-decision between provider and mother is necessary to choose the optimal nutrition for these infants. Each approach will maintain breast milk production. Depending upon the availability of resources, patient volume/surge, parents' under- standing of the potential risk of exposure, we have proposed three options A, B, and C for various steps during the care of a neonate born to a mother with suspected or confirmed COVID-19 (-Fig. 2). There are no official statements from the Human Milk Banking Association of North America regarding screening of donors of breastmilk. However, institutions should be prepared to save donor milk for extremely premature infants secondary to the risk of shortage due to social isolation protocols.

1. Option A (parents and providers prefer to decrease risk of transmission and accept the risk of limited mother-infant bonding and resources are abundant, with relatively low patient volume): the infant receives formula (or donor milk if available). The mother can pump and dump milk until she is asymptomatic with two negative tests for SARS-CoV-2 at least 24-hour apart.

2. Option B (parents and providers prefer to limit risk of transmission and encourage mother-infant bonding and resources are starting to fall behind demand, with modest patient volume): the mother washes her breast with soap and water and expresses milk while wearing a mask. The mother should clean the breast pump tubing and container after each use and preferably have a dedicated breast pump. Strict hand hygiene must be followed. A healthy family member/nurse can feed the expressed milk to the baby in a separate room. This approach continues until the mother meets the same criteria as in option A.

3. Option $C$ (parents and providers prefer to accept risk of transmission and encourage mother-infant bonding or resources and space are limited, with high patient volume): mother wears a surgical mask, washes her hands and breasts with soap and water and breastfeeds the baby. Parents should understand that the risk of transmission with this approach is uncertain but possible. These precautions continue until mother is afebrile (without antipyretics), demonstrates improvement of symptoms and has two negative tests for SARS-CoV-2 at least 24-hour apart. In some instances, if mother and baby are asymptomatic, they are discharged home with further testing only if baby becomes symptomatic.

CDC does not give a clear recommendation among the above choices. WHO supports continuation of breastfeeding with necessary precautions (option C).

\section{Breastfeeding and COVID-19 Specific Therapy}

The safety of breastfeeding when mother is on antiviral therapy remains unknown. There are ongoing trials of remdesivir among patients with COVID-19 (NCT04292899). Nothing is known about the passage of remdesivir into breastmilk. One newborn infant with Ebola was treated with remdesivir and did not experience any adverse events. ${ }^{31}$ The current remdesivir trail only includes adult patients 18 years and older. Pregnancy and breastfeeding are listed as exclusion criteria in some of these trials. Hydroxychloroquine is being considered as a potential therapy for COVID-19. The package insert data state no increase in rates of birth defects in exposed mothers. No ill effects are reported in infants from maternal 
hydroxychloroquine while breastfeeding. Investigational drug sarilumab is an interleukin-6 IgG1 monoclonal antibody and there is no data available on its safety during pregnancy or breastfeeding.

\section{Postnatal Workup and Care of the Neonate}

If the mother is positive for SARS-CoV-2, the infant should be tested at or beyond 24 hours after birth. Separate swabs of the nasopharynx, oropharynx, and rectum are recommended depending on the availability and turnaround time of testing facilities. In our institution, nasopharyngeal swabs are most relevant for clinical intervention due to short turnaround time and in-house availability for testing. Depending on the sensitivity and specificity of the test, a second test 24 hours later may be valuable for confirmation. To date, the literature reports four neonates who have tested positive for SARS-CoV-2 at 36 hours of life. ${ }^{8,18,32}$

\section{Obtaining Real-Time Polymerase Chain Reaction for SARS-CoV-2}

Currently, RT-PCR is considered the gold standard for diagnosis of SARS-CoV-2. ${ }^{33} \mathrm{CDC}$ recommendations should be followed while collecting diagnostic tests from a PUI. ${ }^{33}$ A nasopharyngeal swab is preferably obtained in a negative pressure room or in isolation with adequate PPE (fit-tested mask/PAPR/face mask depending upon the supply, goggles/face shield, and gown). After obtaining the sample, PPE should be discarded and the room where the swabs were obtained should be cleaned.

As per the Chinese expert consensus on the perinatal and neonatal management for the prevention and control of the COVID-19 infection, ${ }^{11}$ a positive RT-PCR for the nucleic acid of the SARS-CoV-2 virus from either the nasopharyngeal/oropharyngeal or rectal swab is sufficient for diagnosis. Some institutions do not have the capability of testing rectal swabs at this time. The accuracy of RT-PCR could be affected by the lack of harmonization in the procedure, for example, the difference in primers and probes. ${ }^{34}$ European countries employ nine primers as compared with three primers used routinely. ${ }^{34,35}$ Infants under investigation for COVID-19 could be cared for in an isolette if a negative pressure room is not available. Contact and droplet precautions should continue as recommended by $\mathrm{CDC}^{6,9}$ In places with surge status, health care providers and attendees are all routinely screened for symptoms and signs of COVID-19 in the NICU.

\section{Care of a Preterm or Symptomatic Term Infant in the NICU}

Infants born preterm or term with other pathology may necessitate care in the NICU. If a newborn with COVID-19 exhibits respiratory symptoms, a chest X-ray is indicated. A diffuse ground glass appearance has been described in adults, but the radiographic features of neonates with lower respiratory tract infection due to SARS-CoV-2 have not been well characterized. In the NICU, these infants should be cared for in an isolette in a negative pressure room. Contact and droplet precautions are recommended unless the infant is undergoing aerosol-generating procedures, such as deep suctioning, CPAP, intubation/extubation, or mechanical ven- tilation, in which case, airborne precautions (PAPR or N95 mask plus goggles, gloves, and gown) are indicated. Given the common use of uncuffed tubes, both conventional ventilators and high-frequency ventilators include some risk of aerosolization. The oxygen filters, tubing for the ventilator, face mask, and any other device as part of the respiratory management should be disposed or carefully sterilized depending upon the availability of resources. The number of providers in the room is restricted with proper disposal of any PPE used to care for a PUI or a confirmed COVID-19.

\section{Symptomatic Newborn (Early-Onset Disease)}

Zeng et al describe the characteristics of three symptomatic COVID-19 neonates born to mothers who tested positive for SARS-CoV-2 by RT-PCR. ${ }^{32}$ Two of these neonates were term $\left(40^{4 / 7}\right.$ weeks), and one was preterm at $31^{2 / 7}$ weeks. Chest imaging in all three neonates demonstrated signs of pneumonia. The preterm infant had features of respiratory distress syndrome and pneumonia with signs of sepsis and coagulopathy. $\mathrm{He} /$ she required noninvasive mechanical ventilation and antibiotic therapy. Other clinical features noted/included are fever, tachypnea, feeding intolerance and cyanosis (-Fig. 4). Laboratory analysis revealed leukocytosis, lymphopenia, thrombocytopenia, and elevated creatinine kinase-MB fraction. The RT-PCR for SARS-CoV-2 from nasopharyngeal and anal swabs were positive on days 2 and 4 for all three neonates and was negative after day 6 . There is no evidence to date that administration of immunoglobulins, antivirals, and steroids improves outcomes of neonates with severe COVID-19.

\section{Late-Onset Disease}

Although there are no case reports, late-onset respiratory distress has been described in several infants 1 to 3 weeks after birth and/or discharge. These cases likely represent postnatally acquired disease and generally are mild and selfresolved. Once an infant is discharged, there is at least $15 \%$ or higher chance of horizontal transmission from household contacts in the absence of transmission barriers. ${ }^{36}$

\section{Management of a Neonate Exposed to a COVID-19 Positive Health Care Provider/Visitor}

In the hospital setting, preterm infants and neonates with comorbidities have a longer length of stay and a higher risk of exposure to SARS-CoV-2 in the hospital. Depending upon the resources and patient volume, we propose three options to manage these neonates in -Table 1. Given the widespread community prevalence of COVID-19 in the United States, many Public Health agencies are not testing contacts unless they are symptomatic. However, based on the Korean experience with more widespread testing, the biological behavior/habit of the virus could provide valuable information. ${ }^{35}$

\section{Discharge and Posthospital Care}

To date, there have been no reports of mortality reported in infants with COVID-19. ${ }^{32,37,38}$ A healthy caregiver may care for the newborn until mother is afebrile (without antipyretics), demonstrates improvement of symptoms and has two negative tests for SARS-CoV-2 at least 24-hour apart. 

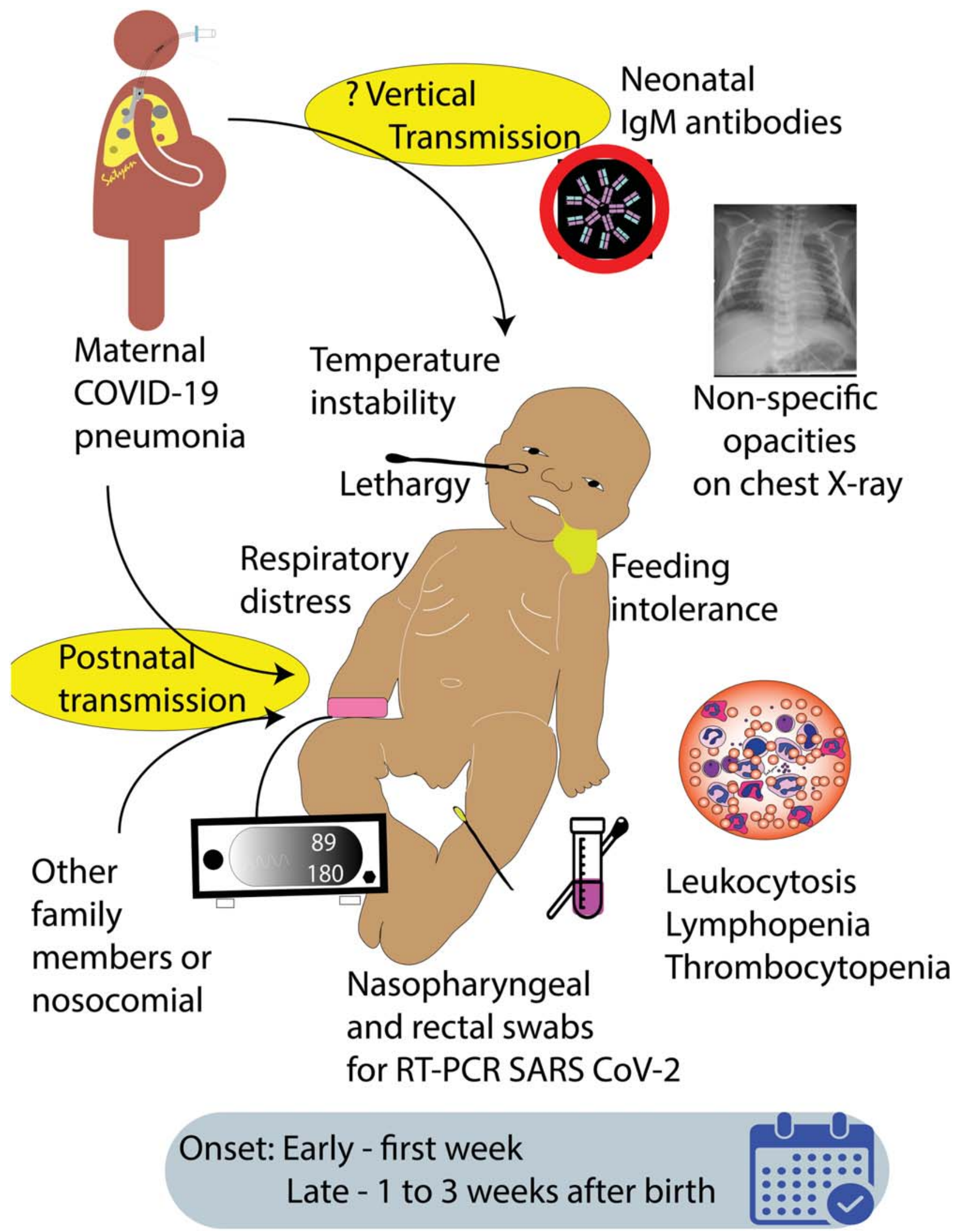

Fig. 4 Exposure to COVID-19 during the perinatal period and the possible clinical signs and symptoms along with laboratory changes in a newborn. The disease may be classified into early onset or late-onset. COVID-19, novel coronavirus disease 2019; Ig, immunoglobulin; RT-PCR, real-time polymerase chain reaction; SARS-CoV-2, severe acute respiratory syndrome-coronavirus 2. Image Courtesy: Satyan Lakshminrusimha. 
If the social situation does not favor separation from mother, discharge of the neonate with droplet and adequate precaution is recommended. If initial testing is negative in the infant, repeat testing could be considered depending on the clinical situation taking into account development of signs, exposure to known cases, etc.

Although the severity of COVID-19 is less in the pediatric age group compared with adults, Dong et al have shown that infants are vulnerable. ${ }^{39,40}$ Thus, follow-up of neonates confirmed to have COVID-19 with repeat testing is important to prevent disease transmission. Adult studies have shown prolonged fecal shedding of the virus even after the oropharyngeal swabs are negative. ${ }^{41}$ How long the infected neonate sheds SARS-CoV-2 in the feces is unknown. To detect lateonset disease, we recommend close follow-up of mother and infant through video visits or phone calls.

\section{Importance of Limiting Transmission and Reporting}

Effect of the novel coronal virus on pregnancy, vertical transmission, fetal development, and neonatal outcomes remains unknown. With the increasing rates of transmission, and dwindling resources, there is a growing need for accurate data/evidence to inform effective guidelines for perinatal management. ${ }^{42}$ It is imperative to reduce rising fears and optimize strategies to reduce the spread of COVID-19 to neonates and health care workers. Shared decision-making among providers and parents educates and empowers parents and maintains focus on familycentered outcomes.

\section{Conclusion}

With emerging evidence, recommendations for management of perinatal COVID-19 continue to evolve. The approaches summarized here are based on available evidence and personal opinion. These recommendations are subjected to change as more evidence becomes available. The presented approaches provide flexibility and allow perinatal health care providers and parents to determine the best options based on the assessment of risks and benefits, available personnel, space, case load, and resources. In the pandemic of COVID-19, the common ailments of neonates will remain higher on the differential diagnosis. However, the possibility of infection from SARS-CoV-2 should be considered in the ill infant for the foreseeable future. It is also of prime importance that health care providers protect themselves while providing the best care possible.

Note

D.T., P.C., and S.L. are scientific experts associated with ILCOR and S.L. is a member of the steering committee of the American Academy of Pediatrics Neonatal Resuscitation Program. M.V. is the Chairman of the European Board of Neonatology (European Society for Pediatric Research) and the Chairman of the Spanish Maternal, Neonatal, and Developmental Network SAMID (Instituto de Investigación
Sanitaria Carlos III, Ministry of Science and Innovation, Kingdom of Spain). However, the views expressed in this article are individual opinions of the authors and do not reflect official recommendations of these organizations.

Conflict of Interest

None declared.

\section{References}

1 World Health Organization. Coronavirus disease 2019 (COVID-19). Situation Report-74. Updated March 20, 2020. Available at: https:// www.who.int/docs/default-source/coronaviruse/situation-reports/ 20200321-sitrep-61-covid-19.pdf?sfvrsn=6aa18912_2. Accessed April 6, 2020

2 Coronaviridae Study Group of the International Committee on Taxonomy of V. The species severe acute respiratory syndromerelated coronavirus: classifying $2019-\mathrm{nCoV}$ and naming it SARSCoV-2. Nat Microbiol 2020;5:536-544

3 The Gurdian. First Covid-19 case happened in November, China government records show - report. Available at: https://www. theguardian.com/world/2020/mar/13/first-covid-19-case-happened-in-november-china-government-records-show-report. Accessed April 2, 2020

4 Holshue ML, DeBolt C, Lindquist S, et al; Washington State 2019nCoV Case Investigation Team. First case of 2019 novel coronavirus in the United States. N Engl J Med 2020;382(10):929-936

5 Peristats. United States. Quick Facts: Population. Available at: https://www.marchofdimes.org/Peristats/ViewTopic.aspx?reg= 99\&top $=14 \&$ lev $=0 \&$ slev $=1$. Accessed April 2, 2020

6 Centers for Diasase Control and Presention Pregnancy \& breastfeeding information about coronavirus disease 2019. Available at: https://www.cdc.gov/coronavirus/2019-ncov/prepare/pregnancy-breastfeeding.html. Accessed April 2, 2020

7 Chen H, Guo J, Wang C, et al. Clinical characteristics and intrauterine vertical transmission potential of COVID-19 infection in nine pregnant women: a retrospective review of medical records. Lancet 2020;395(10226):809-815

8 Mullins E, Evans D, Viner RM, O’Brien P, Morris E. Coronavirus in pregnancy and delivery: rapid review. Ultrasound Obstet Gynecol 2020

9 Centers for Diasase Control and Presention. Interim Considerations for Infection Prevention and Control of Coronavirus Disease 2019 (COVID-19) in Inpatient Obstetric Healthcare Settings. Available at: https://www.cdc.gov/coronavirus/2019-ncov/hcp/ inpatient-obstetric-healthcare-guidance.html. Accessed April 2, 2020

10 Liu Y, Chen H, Tang K, Guo Y. Clinical manifestations and outcome of SARS-CoV-2 infection during pregnancy. J Infect 2020:S0163-4453(20)30109-2

11 Wang X, Zhou Z, Zhang J, Zhu F, Tang Y, Shen X. A case of 2019 novel coronavirus in a pregnant woman with preterm delivery. Clin Infect Dis 2020:ciaa200

12 Zhu H, Wang L, Fang C, et al. Clinical analysis of 10 neonates born to mothers with 2019-nCoV pneumonia. Transl Pediatr 2020;9 (01):51-60

13 Avery CM. A controlled trial of antepartum glucocorticoid treatment for prevention of the respiratory distress syndrome in premature infants, by G. C. Liggins, MB, PhD, FRCOG, and R. N. Howie, MB, MRACP, Pediatrics, 1972;50:515-525. Pediatrics 1998;102(1, Pt 2):250-251

14 Liggins GC, Howie RN. A controlled trial of antepartum glucocorticoid treatment for prevention of the respiratory distress syndrome in premature infants. Pediatrics 1972;50(04):515-525

15 Klein K, McClure EM, Colaci D, et al. The antenatal corticosteroids trial (ACT): a secondary analysis to explore site differences in a multi-country trial. Reprod Health 2016;13(01):64 
16 Dubler S, Zimmermann S, Fischer M, et al. Bacterial and viral contamination of breathing circuits after extended use - an aspect of patient safety? Acta Anaesthesiol Scand 2016;60(09): $1251-1260$

17 World Health Organizations. Clinical management of severe acute respiratory infection when COVID-19 disease is suspected. Available at: https://www.who.int/publications-detail/clinical-management-of-severe-acute-respiratory-infection-when-novel-coronavirus-(ncov)-infection-is-suspected. Accessed April 2, 2020

18 Wang L, Shi Y, Xiao T, et al. Chinese expert consensus on the perinatal and neonatal management for the prevention and control of the 2019 novel coronavirus infection (first edition). Ann Transl Med 2020;8(03):47

19 Spanish Ministry of Health. Documento técnico Manejo de la mujer embarazada y el recién nacido con COVID-19. Available at: https://www.mscbs.gob.es/en/profesionales/saludPublica/ ccayes/alertasActual/nCov-China/documentos/Documento_ manejo_embarazo_recien_nacido.pdf. Accessed April 2, 2020

20 Schwartz DA. An analysis of 38 pregnant women with COVID-19, their newborn infants, and maternal-fetal transmission of SARSCoV-2: maternal coronavirus infections and pregnancy outcomes. Arch Pathol Lab Med 2020 (e-pub ahead of print). Doi: 10.5858/ arpa.2020-0901-SA

21 Dong L, Tian J, He S, et al. Possible vertical transmission of SARSCoV-2 from an infected mother to her newborn. JAMA 2020

22 Kimberlin DW, Stagno S. Can SARS-CoV-2 infection be acquired in utero?: more definitive evidence is needed JAMA 2020. Doi: 10.1001/jama.2020.4868

23 Zeng H, Xu C, Fan J, et al. Antibodies in infants born to mothers with COVID-19 pneumonia. JAMA 2020

24 World Health Organization. Guidelines on Basic Newborn Resuscitation. Geneva, Switzerland: World Health Organization; 2012

25 Pisacane A. Neonatal prevention of iron deficiency. BMJ 1996;312 (7024):136-137

26 Sanberg PR, Park DH, Borlongan CV. Stem cell transplants at childbirth. Stem Cell Review Report 2010;6:27-30

27 Andersson O, Lindquist B, Lindgren M, Stjernqvist K, Domellöf M, Hellström-Westas L. Effect of delayed cord clamping on neurodevelopment at 4 years of age: a randomized clinical trial. JAMA Pediatr 2015;169(07):631-638

28 American Academy of Pediatrics and American Heart Association; Weiner GM, Zaichkin J, eds. Textbook of Neonatal Resuscitation (NRP). 7th ed. Grove Village, IL: American Academy of Pediatrics; 2016:326

29 Schmölzer GM, Dawson JA, Kamlin CO, O'Donnell CP, Morley CJ, Davis PG. Airway obstruction and gas leak during mask ventila- tion of preterm infants in the delivery room. Arch Dis Child Fetal Neonatal Ed 2011;96(04):F254-F257

30 Cheung JC, Ho LT, Cheng JV, Cham EYK, Lam KN. Staff safety during emergency airway management for COVID-19 in Hong Kong. Lancet Respir Med 2020:S2213-2600(20)30084-9

31 Anderson PO. Breastfeeding and respiratory antivirals: coronavirus and influenza. Breastfeed Med 2020;15(03):128

32 Zeng L, Xia S, Yuan W, et al. Neonatal early-onset infection with SARS-CoV-2 in 33 neonates born to mothers with COVID-19 in Wuhan, China. JAMA Pediatr 2020

33 Centers for Diasase Control and Presention. Interim Infection Prevention and Control Recommendations for Patients with Suspected or Confirmed Coronavirus Disease 2019 (COVID-19) in Healthcare Settings. Available at: https://www.cdc.gov/coronavirus/2019-ncov/infection-control/control-recommendations.html\#take_precautions. Accessed April 2, 2020

34 Lippi G, Simundic A-M, Plebani M. Potential preanalytical and analytical vulnerabilities in the laboratory diagnosis of coronavirus disease 2019 (COVID-19). Clin Chem Lab Med 2020 (e-pub ahead of print). Doi: 10.1515/cclm-2020-0285

35 Li D, Wang D, Dong J, et al. False-negative results of real-time reverse-transcriptase polymerase chain reaction for severe acute respiratory syndrome coronavirus 2: role of deep-learning-based CT diagnosis and insights from two cases. Korean J Radiol 2020;21 (04):505-508

$36 \mathrm{Bi} \mathrm{Q}, \mathrm{Wu}$ Y, Mei S, et al. Epidemiology and transmission of COVID-19 in Shenzhen China: analysis of 391 cases and 1,286 of their close contacts. medRxiv 2020. Doi: 10.1101/2020.03.03.20028423

37 Livingston E, Bucher K. Coronavirus disease 2019 (COVID-19) in Italy. JAMA 2020

38 Wei M, Yuan J, Liu Y, Fu T, Yu X, Zhang ZJ. Novel coronavirus infection in hospitalized infants under 1 year of age in China. JAMA 2020;323(13):1313-1314

39 COVID-19 in children: initial characterization of the pediatric disease. Pediatrics 2020 (e-pub ahead of print). Doi:10.1542/ peds.2020-0834

40 Dong Y, Mo X, Hu Y, et al. Epidemiological characteristics of 2143 pediatric patients with 2019 coronavirus disease in China. Pediatrics 2020 (e-pub ahead of print). Doi: 10.1542/peds.20200702

$41 \mathrm{Wu}$ Y, Guo C, Tang L, et al. Prolonged presence of SARS-CoV-2 viral RNA in faecal samples. Lancet Gastroenterol Hepatol 2020 (e-pub ahead of print). Doi: 10.1016/S2468-1253(20)30083-2

42 Bauchner H, Golub RM, Zylke J. Editorial concern-possible reporting of the same patients with covid-19 in different reports. JAMA 2020 (e-pub ahead of print). Doi: 10.1001/jama.2020.3980 